\title{
Autonomic nerve regulation for prostate cancer: study based on the tissue transcriptional analysis
}

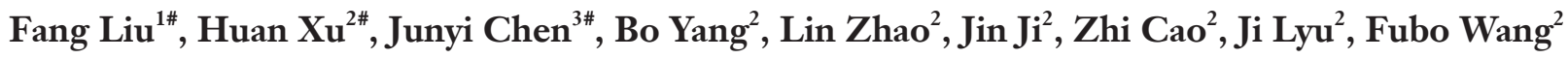 \\ ${ }^{1}$ Department of Urology, Pingxiang People's Hospital, Pingxiang, China; ${ }^{2}$ Department of Urology, Shanghai Changhai Hospital, Second Military \\ Medical University, Shanghai, China; ${ }^{3}$ Department of Urology, the Second Affiliated Hospital of Fujian Medical University, Quanzhou, China \\ Contributions: (I) Conception and design: H Xu; (II) Administrative support: F Wang; (III) Provision of study materials or patients: F Liu, J Chen, J \\ Lyu; (IV) Collection and assembly of data: B Yang; (V) Data analysis and interpretation: L Zhao, J Ji, Z Cao; (VI) Manuscript writing: All authors; (VII) \\ Final approval of manuscript: All authors. \\ "These authors contributed equally to this work. \\ Correspondence to: Fubo Wang. Department of Urology, Shanghai Changhai Hospital, Second Military Medical University, 168 Changhai Road, \\ Shanghai, China. Email: fubowang@smmu.edu.cn.
}

Background: The whole-body energy metabolism is regulated by autonomic nerves which also play important roles in the regulation of the generation and development of different kinds of cancers. This study is to analyze the expression of autonomic nerve receptors and their relationship with the development of prostate cancer $(\mathrm{PCa})$ and to further understand the central regulation of the prostate.

Methods: RNA sequencing data concerning autonomic nerve receptors from paired tumor and adjacent benign tissues from 65 patients were collected. The mRNA expression and patient data were analyzed. The Cancer Genome Atlas (TCGA) data confirmed the results, and Pearson analysis, Pearson heat maps, gene heat maps, multivariate logistic regression models, receiver operating characteristic (ROC) curves and Gene Set Enrichment Analysis (GSEA) and Pearson's analysis were analyzed for correlation analysis in this study.

Results: Reads with eight receptors associated with PCa generation were finally retained in this report. Favorable relationships were found among the different autonomic nerve regulators for the prostate. In univariate logistic regression analysis, adrenoceptor alpha 1A (ADRA1A) was the most positively correlated [OR (95\% CI): 1.707 (1.209, 2.410)]; the area under the curve (AUC) in the ROC for ADRA1A was 0.866 $(\mathrm{P}<0.001)$. In multivariate logistic regression analysis, a predicted formulation for $\mathrm{PCa}$ diagnosis was evident. The GSEA results also showed the effect of autonomic nerves on cancer generation and some of the key cancer-related pathways, as well as Notch, Wnt and steroid biosynthesis pathways. Finally, five articles were reviewed to elucidate the center-autonomic nerve system-periphery circuit in the prostate.

Conclusions: Central regulation plays an important role in the development of PCa, presenting the opportunity to treat the disease, and additional studies are warranted.

Keywords: Autonomic nerve; prostate cancer (PCa); sympathetic nervous system (SNS); parasympathetic nervous system (PSNS)

Submitted May 10, 2020. Accepted for publication Oct 09, 2020.

doi: $10.21037 /$ tcr-20-2053

View this article at: http://dx.doi.org/10.21037/tcr-20-2053

\section{Introduction}

Autonomic nerves play important roles in the regulation of whole-body energy metabolism. Different from the sensory and motor nerves, which mediate muscular movement for the reaction to the surroundings, autonomic nerves regulate the local tissues to adapt to the surrounding microenvironment. Autonomic nervous system internal organs interact with peripheral tissues and the central nervous system. The autonomic nervous system is one of the most widely distributed systems that regulates the biochemical 
process of various tissues and organs, and the peripheral nervous system is a neuronal circuit and connection between the body parts and the central nervous system. There are two types of autonomic nerves, synthetic and para-synthetic nerves, which play roles according to the various receptors in different organs or tissues.

Prostate cancer (PCa) is the second most frequently diagnosed cancer and has the fifth highest mortality in males (1). Different from many other cancers, PCa can be completely cured if it is treated in its early stage. Surgery and radiation are standard therapy for localized $\mathrm{PCa}$. However, it is much harder to treat advanced PCa, especially PCa with bone metastases. Prostate-specific antigen (PSA) remains the most wildly used biomarker for PCa, though its use in detecting PCa early is limited. Recently, there are more and more methods used for the early detection, including some specific mRNA, lncRNA as well as exosomes. The markers such as PSMA as well as AMACR are more wildly used in the early diagnosis and prognosis.

Interestingly, in vitro coculture experiments have shown that sensory neurons from the dorsal root ganglion promote PCa cell proliferation (2), and many sympathetic and parasympathetic nerves are abundantly innervated in the prostate stroma, contributing to the growth and metastasis of the PCa $(3,4)$. Thus, autonomic nerves, as one of the most important influencing factors in vivo, contribute to the generation and development of the PCa.

Currently, emerging studies suggest that the nervous system tends to contribute much to tumorigenesis and tumor progression. In the prostate of human beings, there is evidence for high expression of muscarinic 1 (M1) receptors in the epithelium and M2 receptors in the stroma $(5,6)$. There are both $M 1$ and $M 3$ receptors in some PCa cell lines. The muscarinic receptors may regulate benign hyperplasia and malignant prostate progress (7). In vitro, as reported previously, acetylcholine (Ach) tends to induce the proliferation of $\mathrm{PCa}$ cell lines via cholinergic receptor muscarinic 1 (CHRM1) and CHRM3 (7). In vivo work suggests that neural stimulation elevates the tumor incidence and metastases. Clinical research also indicates that patients taking $\beta$-blockers present with lower tumor recurrence rates and mortality in some cancers, including breast cancer and PCa. Some previous reports showed that the production of nervous system signals are critical at the early stages of prostate tumor development in a xenogeneic mouse model (8). As suggested, the tumor recruits newly formed nerves in the prostate stroma, which forms the microenvironment and accelerates the process of $\mathrm{PCa}$ $(8,9)$. Sympathetic nerve fibers deliver adrenergic signals (norepinephrine) from nerve termini that act in the tumor microenvironment, promoting the survival of cancer cells and initial development of the tumor. Moreover, with the development of transneuronal tracing, pseudorabies virus (PRV), a self-amplifying virus tracer, can detect the central zone controlling the development of the prostate gland $(2,10,11)$. In this way, it is possible to recognize the central zone for 'center-autonomic nerve-prostate' regulation.

In this study, we analyzed the RNA sequencing database and public database to study the expression and relationship between autonomic nerve receptors and the generation as well as development of PCa. Furthermore, a literature review was performed concerning the central control of the prostate. We present the following article in accordance with the MDAR reporting checklist (available at http:// dx.doi.org/10.21037/tcr-20-2053).

\section{Methods}

\section{Patients and samples}

Prostate tumor and matched normal tissues were collected from the radical prostatectomy series at Shanghai Changhai Hospital. The study conformed to the provisions of the Declaration of Helsinki (as revised in 2013). Written informed consents were obtained from the participants before sampling. The study was approved by the Clinical Research Ethics Committee of Shanghai Changhai Hospital of Second Military Medical University (No. 2017JZ35). The diagnosis was conducted with the help of a pathologist using hematoxylin and eosin ( $\mathrm{H} \& \mathrm{E})$ and immunohistochemical slides of human tissues. Finally, the RNA sequencing data concerning the receptors of autonomic nerves from paired tumor and adjacent benign tissues were collected from these 65 patients (age: $68.8 \pm 10.8 \mathrm{yrs}$ ). The method used was reported previously (12) to quantify the gene expression according to the protocol and manual for each patient.

\section{Data collection from the public database}

The Cancer Genome Atlas (TCGA) (https://cancergenome. nih.gov/) was employed for this cancer analysis. For normal tissue expression, the Human Protein Atlas (https://www. proteinatlas.org/) was utilized. The data were collected and analyzed according to the patient details provided by the public database. The receptors were collected according to 
their expression level and the significance between normal tissue and cancer tissue.

\section{Data preprocessing and reads mapping}

Pearson analysis was used to detect the relationship among different autonomic nerve receptors as well as the receptor expression and different clinical stages. Pearson heat maps were constructed according to the results of Pearson analysis. Multivariate logistic regression models were calculated by stepwise selection of the most significant predictors on univariate analysis. Receiver operating characteristic (ROC) curves were plotted to detect the relationship between autonomic nerve receptors and the PCa diagnosis. Gene Set Enrichment Analysis (GSEA) was conducted on Gene Set Enrichment Analysis Software (Broad Institute, Cambridge, MA, USA).

\section{Collection of reviewed research}

Papers published about the retrograde tracing technique and prostate were analyzed to study the circuit between the central nervous system control and peripheral PCa generation and development.

\section{Statistical analysis}

A two-sided $\mathrm{P}<0.05$ was considered statistically significant. Pearson heat maps and multivariate logistic regression were utilized in different analyses. All the above data were analyzed using SPSS software version 19,0 (IBM Corp., Armonk, NY, USA).

\section{Results}

\section{Expression of autonomic nerve receptors}

Reads with non-significant bases or of low quality were removed, and eight receptors were finally retained in this report: adrenoceptor alpha 1A (ADRA1A), ADRA2A, adrenoceptor beta 1 (ADRB1), ADRB2, CHRM1, CHRM3, cholinergic receptor nicotinic alpha 1 subunit (CHRNA2) and CHRNA5. The data are shown in Figure 1, including analysis of the results from our own database and public database. In the TCGA database, ADRA1A and ADRA2A were significantly lowly-expressed $(\mathrm{P}<0.01)$ in the cancer tissue compared with those in the normal tissues. In our data analysis, the ADRA1A result was similar, while no difference was observed in the variation of ADRA2A. In TCGA, the ADRB1, ADRB2, CHRM1, CHRM3, CHRNA2 and CHRNA5 expression levels were significantly elevated $(\mathrm{P}<0.001)$ compared with those in normal individuals. However, in our database, collected from Chinese individuals, CHRM1 was significantly reduced in $\mathrm{PCa}$ tissues compared with that in paracancerous tissue $(\mathrm{P}<0.001)$. Multivariate logistic regression presented in Table 1 shows that ADRA1A is most closely positively related to $\mathrm{PCa}[\mathrm{OR}=1.707(1.209,2.410)$, $\mathrm{P}=0.002]$. It is also significant for ADRB 1 [OR $=0.754$ (0.625, 0.910), $\mathrm{P}=0.003$ ] and CHRM1 [OR =1.181 (1.040, 1.341), $\mathrm{P}=0.010]$.

\section{Pearson analysis among different autonomic nerve receptors}

To study the correlation among different receptors and effect of varied effects on sympathetic nervous (SN) and parasympathetic nervous system (PSNS), Pearson analysis among different autonomic nerve receptors was performed. As shown in Table 2 and Figure S1, ADRB1 and ADRB2 were positively related $(\mathrm{P}<0.001)$, and $A D R B 2$ was negatively related, to the expression levels of ADRA2A, ADRA1A, CHRM1 and CHRNA5. The CHRM1 level was positively related to the ADRA1A and CHRNA2 levels but negatively related to the CHRM3 level.

\section{GSEA of the autonomic nerve receptor expression}

Because it was found that numerous receptors are related to PCa development, GSEA was used to study the possible effect and mechanisms of these autonomic nerve receptors. Based on this analysis, the 20 most significantly altered pathways are shown in Figure 1, at the most significantly changed receptors which include ADRA1A and ADRB1. ADRA1A was closely related to cancer signaling, and both were related to different cancer-relating signaling pathways, including Wnt, NOTCH and steroid biosynthesis pathways, with lower $\mathrm{P}$ values. These results may present some clues for the further study of the detailed mechanisms of this effect.

\section{Literature review of the studies of retrograde tracing techniques and the prostate}

As is widely known, the effect of stress on blood pressure and the glucose level is regulated by the hypothalamic- 


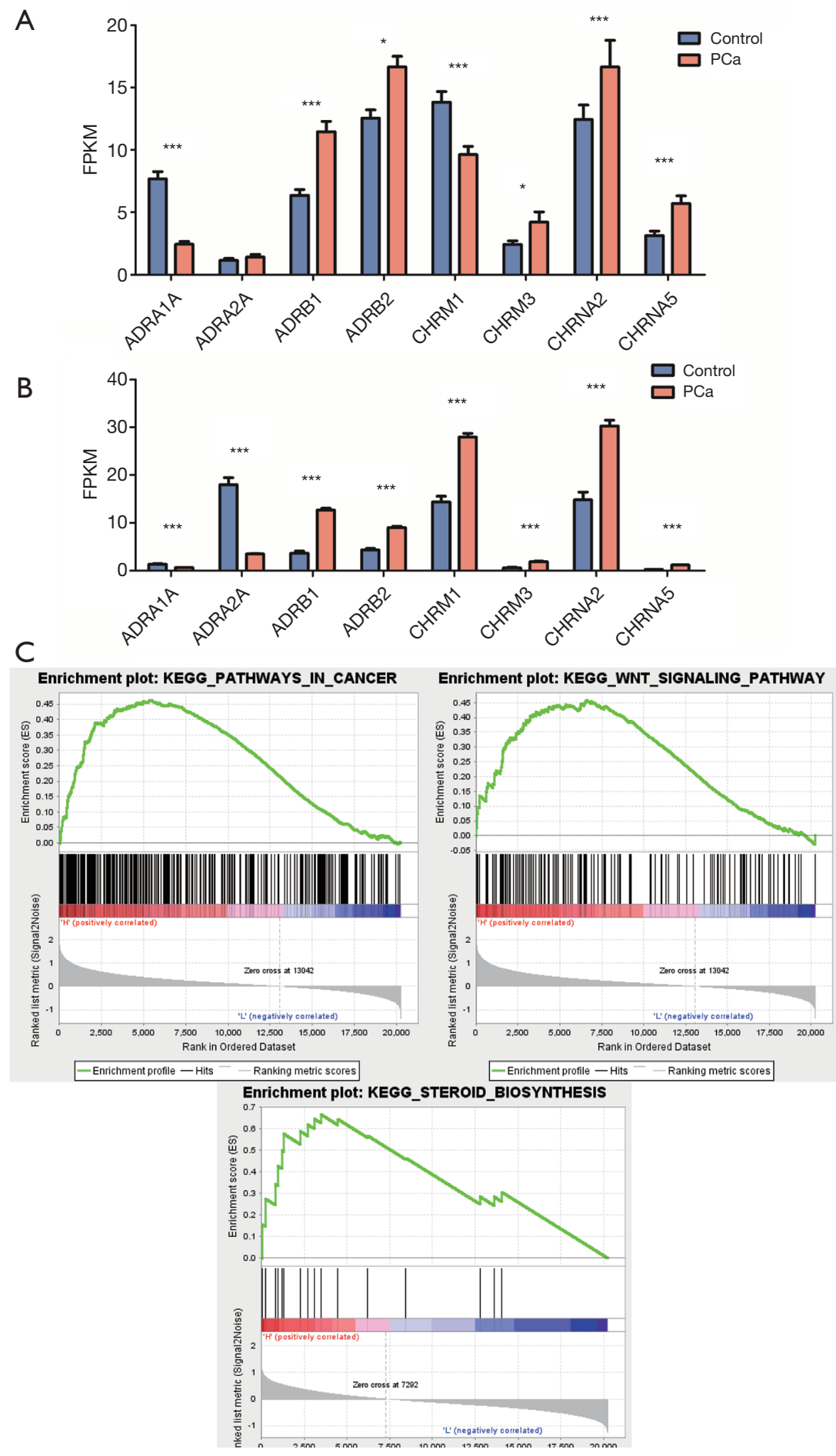

Figure 1 mRNA expression levels of the various autonomic nerve receptors. (A) Receptor mRNA expression levels in our database; (B) receptor mRNA expression levels from the TCGA database; (C) significant GSEA results of mRNA for various types of significantly changed autonomic nerve receptors. The top two are GSEA of ADRA1A and the bottom one is ADRB1. * $\mathrm{P}<0.05 ;$ ***, $\mathrm{P}<0.001$. Error bars indicate SEM. TCGA, The Cancer Genome Atlas; GSEA, Gene Set Enrichment Analysis; ADRA, adrenoceptor alpha; ADRB, adrenoceptor beta; CHRM, cholinergic receptor, muscarinic; CHRNA, cholinergic receptor nicotinic alpha; PCa, prostate cancer; SEM, standard error of the mean. 
Table 1 Multivariate logistic regression models

\begin{tabular}{llc}
\hline Characteristics & P value & OR $(95 \% \mathrm{Cl})$ \\
\hline ADRB1 & $0.003^{\star *}$ & $0.754(0.625,0.910)$ \\
ADRA1A & $0.002^{\star *}$ & $1.707(1.209,2.410)$ \\
ADRA2A & 0.099 & $0.603(0.330,1.099)$ \\
ADRB2 & 0.370 & $0.950(0.848,1.063)$ \\
CHRNA2 & 0.720 & $1.011(0.953,1.072)$ \\
CHRM3 & 0.073 & $0.805(0.635,1.020)$ \\
CHRM1 & $0.010^{*}$ & $1.181(1.040,1.341)$ \\
CHRNA5 & 0.607 & $0.953(0.793,1.145)$ \\
\hline
\end{tabular}

*, Correlation is significant at the 0.05 level (two-tailed); ${ }^{* *}$, correlation is significant at the 0.01 level (two-tailed). ADRA, adrenoceptor alpha; ADRB, adrenoceptor beta; CHRM, cholinergic receptor, muscarinic; CHRNA, cholinergic receptor nicotinic alpha. pituitary-adrenal axis, also indicating that the central nervous system contributes to whole-body hemostasis after the implicated brain nuclei (13). The concise connection between the central and peripheral organs is the autonomic nerve system (14). PRV can label the entire circuits within the same animal through its infection of only functionally connected neurons, and it is frequently utilized in the retrograde tracing technique for central control of the peripheral organs, including the prostate (11). Studies concerning the retrograde tracing technique and prostate to detect the controlling neurons in the spine or brain are shown in Table 3. Five articles about the retrograde tracing technique used in the prostate were included. They discuss the central control of the prostate using PRV, a transneuronal and viral retrograde tract tracer, which can be microinjected into the prostate gland to label the center-

Table 2 Correlations from TCGA and data analysis

\begin{tabular}{|c|c|c|c|c|c|c|c|c|}
\hline Characteristics & ADRB1 & ADRB2 & ADRA2A & ADRA1A & CHRNA2 & CHRM3 & CHRM1 & CHRNA5 \\
\hline \multicolumn{9}{|l|}{ ADRB1 } \\
\hline Pearson correlation & 1 & $0.304^{\star \star}$ & $-0.159^{\star \star}$ & $-0.107^{*}$ & $0.134^{\star *}$ & -0.016 & -0.018 & 0.037 \\
\hline Sig. (two-tailed) & & 0.000 & 0.000 & 0.024 & 0.003 & 0.732 & 0.697 & 0.418 \\
\hline \multicolumn{9}{|l|}{ ADRB2 } \\
\hline Pearson correlation & $0.304^{\star \star}$ & 1 & $-0.166^{\star \star}$ & $-0.130^{\star \star}$ & -0.077 & 0.026 & $-0.119^{\star *}$ & $-0.145^{\star \star}$ \\
\hline Sig. (two-tailed) & 0.000 & & 0.000 & 0.006 & 0.087 & 0.569 & 0.008 & 0.001 \\
\hline $\mathrm{N}$ & 494 & 494 & 493 & 450 & 493 & 465 & 494 & 494 \\
\hline Sig. (two-tailed) & 0.000 & 0.000 & & 0.532 & 0.163 & 0.867 & 0.053 & 0.000 \\
\hline $\mathrm{N}$ & 493 & 493 & 493 & 450 & 492 & 465 & 493 & 493 \\
\hline \multicolumn{9}{|l|}{ ADRA1A } \\
\hline Pearson correlation & $-0.107^{\star}$ & $-0.130^{\star *}$ & 0.030 & 1 & -0.010 & -0.062 & $0.096^{\star}$ & -0.073 \\
\hline Sig. (two-tailed) & 0.024 & 0.006 & 0.532 & & 0.841 & 0.196 & 0.042 & 0.124 \\
\hline $\mathrm{N}$ & 450 & 450 & 450 & 450 & 449 & 434 & 450 & 450 \\
\hline \multicolumn{9}{|l|}{ CHRNA2 } \\
\hline Pearson correlation & $0.134^{\star \star}$ & -0.077 & -0.063 & -0.010 & 1 & $-0.126^{\star \star}$ & $0.499^{\star \star}$ & $0.256^{\star \star}$ \\
\hline
\end{tabular}

Table 2 (continued) 
Table 2 (continued)

\begin{tabular}{|c|c|c|c|c|c|c|c|c|}
\hline Characteristics & ADRB1 & ADRB2 & ADRA2A & ADRA1A & CHRNA2 & CHRM3 & CHRM1 & CHRNA5 \\
\hline \multicolumn{9}{|l|}{ CHRM3 } \\
\hline Pearson correlation & -0.016 & 0.026 & -0.008 & -0.062 & $-0.126^{\star \star}$ & 1 & $-0.152^{\star \star}$ & 0.008 \\
\hline Sig. (two-tailed) & 0.732 & 0.569 & 0.867 & 0.196 & 0.006 & & 0.001 & 0.864 \\
\hline \multicolumn{9}{|l|}{ CHRM1 } \\
\hline Pearson correlation & -0.018 & $-0.119^{\star \star}$ & 0.087 & $0.096^{*}$ & $0.499^{\star \star}$ & $-0.152^{\star \star}$ & 1 & 0.030 \\
\hline Sig. (two-tailed) & 0.697 & 0.008 & 0.053 & 0.042 & 0.000 & 0.001 & & 0.503 \\
\hline $\mathrm{N}$ & 494 & 494 & 493 & 450 & 493 & 465 & 494 & 494 \\
\hline Sig. (two-tailed) & 0.418 & 0.001 & 0.000 & 0.124 & 0.000 & 0.864 & 0.503 & \\
\hline $\mathrm{N}$ & 494 & 494 & 493 & 450 & 493 & 465 & 494 & 494 \\
\hline \multicolumn{9}{|c|}{ Correlations from data analysis } \\
\hline \multicolumn{9}{|l|}{ ADRB1 } \\
\hline Pearson correlation & 1 & $-0.247^{\star \star}$ & -0.14 & $0.374^{* *}$ & $0.494^{\star \star}$ & -0.012 & $0.236^{\star *}$ & $0.379^{\star \star}$ \\
\hline Sig. (two-tailed) & & 0.005 & 0.111 & 0 & 0 & 0.894 & 0.007 & 0 \\
\hline $\mathrm{N}$ & 130 & 130 & 130 & 130 & 130 & 130 & 130 & 130 \\
\hline \multicolumn{9}{|l|}{ ADRB2 } \\
\hline Sig. (two-tailed) & 0.111 & 0.054 & & 0.253 & 0.164 & 0.019 & 0.712 & 0.001 \\
\hline $\mathrm{N}$ & 130 & 130 & 130 & 130 & 130 & 130 & 130 & 130 \\
\hline \multicolumn{9}{|l|}{ ADRA1A } \\
\hline Pearson correlation & $0.374^{\star \star}$ & $-0.308^{\star \star}$ & 0.101 & 1 & $0.236^{\star \star}$ & -0.046 & $0.210^{\star}$ & 0.048 \\
\hline Sig. (two-tailed) & 0 & 0 & 0.253 & & 0.007 & 0.602 & 0.017 & 0.588 \\
\hline $\mathrm{N}$ & 130 & 130 & 130 & 130 & 130 & 130 & 130 & 130 \\
\hline \multicolumn{9}{|l|}{ CHRNA2 } \\
\hline Pearson correlation & $0.494^{\star *}$ & -0.093 & -0.123 & $0.236^{\star \star}$ & 1 & 0.064 & $0.349^{\star *}$ & $0.294^{\star \star}$ \\
\hline Sig. (two-tailed) & 0 & 0.295 & 0.164 & 0.007 & & 0.472 & 0 & 0.001 \\
\hline $\mathrm{N}$ & 130 & 130 & 130 & 130 & 130 & 130 & 130 & 130 \\
\hline
\end{tabular}

Table 2 (continued) 
Table 2 (continued)

\begin{tabular}{|c|c|c|c|c|c|c|c|c|}
\hline Characteristics & ADRB1 & ADRB2 & ADRA2A & ADRA1A & CHRNA2 & CHRM3 & CHRM1 & CHRNA5 \\
\hline Pearson correlation & -0.012 & -0.098 & $0.206^{*}$ & -0.046 & 0.064 & 1 & 0.076 & -0.04 \\
\hline Sig. (two-tailed) & 0.894 & 0.266 & 0.019 & 0.602 & 0.472 & & 0.393 & 0.652 \\
\hline $\mathrm{N}$ & 130 & 130 & 130 & 130 & 130 & 130 & 130 & 130 \\
\hline Pearson correlation & $0.236^{\star \star}$ & $0.315^{\star \star}$ & -0.033 & $0.210^{*}$ & $0.349^{\star \star}$ & 0.076 & 1 & -0.039 \\
\hline Sig. (two-tailed) & 0.007 & 0 & 0.712 & 0.017 & 0 & 0.393 & & 0.657 \\
\hline $\mathrm{N}$ & 130 & 130 & 130 & 130 & 130 & 130 & 130 & 130 \\
\hline \multicolumn{9}{|l|}{ CHRNA5 } \\
\hline $\mathrm{N}$ & 130 & 130 & 130 & 130 & 130 & 130 & 130 & 130 \\
\hline
\end{tabular}

${ }^{*}$, Correlation is significant at the 0.05 level (two-tailed); ${ }^{*}$, correlation is significant at the 0.01 level (two-tailed). TCGA, The Cancer Genome Atlas; ADRA, adrenoceptor alpha; ADRB, adrenoceptor beta; CHRM, cholinergic receptor, muscarinic; CHRNA, cholinergic receptor nicotinic alpha.

Table 3 Literature review of the PRV retro-grade tracing for prostate

\begin{tabular}{|c|c|c|c|c|}
\hline $\begin{array}{l}\text { Publication } \\
\text { date }\end{array}$ & Authors & Neuron location & Conclusion & $\begin{array}{l}\text { Labelled } \\
\text { organs }\end{array}$ \\
\hline 1998 & $\begin{array}{l}\text { Orr et al. } \\
(15)\end{array}$ & $\begin{array}{l}\text { Spinal interneurons: T13-S1, DGC; brain: gigantocellularisand } \\
\text { paragigantocellularis nucleus (subregion of the medullary } \\
\text { reticular formation), raphe magnus, raphe pallidus, A5 } \\
\text { noradrenergic cell region (pontine tegmentum), Barrington's } \\
\text { nucleus (ventromedial to the LC), central gray, ventral tegmental } \\
\text { area (midline on the floor of the midbrain) and medial preoptic } \\
\text { area (part of hypothalamu) }\end{array}$ & $\begin{array}{l}\text { There exist sympathetic and } \\
\text { parasympathetic spinal circuits and } \\
\text { supraspinal innervation }\end{array}$ & $\begin{array}{l}\text { Ventral } \\
\text { prostate }\end{array}$ \\
\hline 2000 & $\begin{array}{l}\text { Zermann } \\
\text { et al. (2) }\end{array}$ & $\begin{array}{l}\text { Spinal interneurons: sacral (S1-S2) and the thoracolumbar } \\
\text { (T13-L2) spinal cord; brain: nucleus raphe, lateral reticular } \\
\text { formation, gigantocellularis nucleus, A5 noradrenergic cell } \\
\text { region, LC, pontine micturition center, hypothalamus, medial } \\
\text { preoptic region (part of hypothalamus), and periaquaductal } \\
\text { gray (part of midbrain) }\end{array}$ & $\begin{array}{l}\text { It shows central neurons control in the } \\
\text { prostate gland and the innervation of } \\
\text { pelvic visceral organs (bladder, rectum, } \\
\text { and urethra) }\end{array}$ & Prostate \\
\hline 2007 & $\begin{array}{l}\text { Huddleston } \\
\text { et al. (11) }\end{array}$ & $\begin{array}{l}\text { Brain: the controlling neurons are with AR or ER } \\
\text { immunoreactivity in the medial preoptic area, median preoptic } \\
\text { nucleus, bed nucleus of stria terminalis (ventricular surface } \\
\text { of the thalamus), hypothalamic PVN, and zona incerta } \\
\text { (subthalamus below the thalamus) }\end{array}$ & $\begin{array}{l}\text { Collectively, a steroid } \\
\text { receptor-containing neuronal circuit, } \\
\text { largely contained in the diencephalon, } \\
\text { was likely involved in the autonomic } \\
\text { control of prostate }\end{array}$ & Prostate \\
\hline
\end{tabular}

PRV, pseudorabies virus; DGC, dorsal gray commissure; LC, locus coeruleus; DH, dorsal horn; SPN, sacral parasympathetic nucleus; PVN, paraventricular nucleus. 


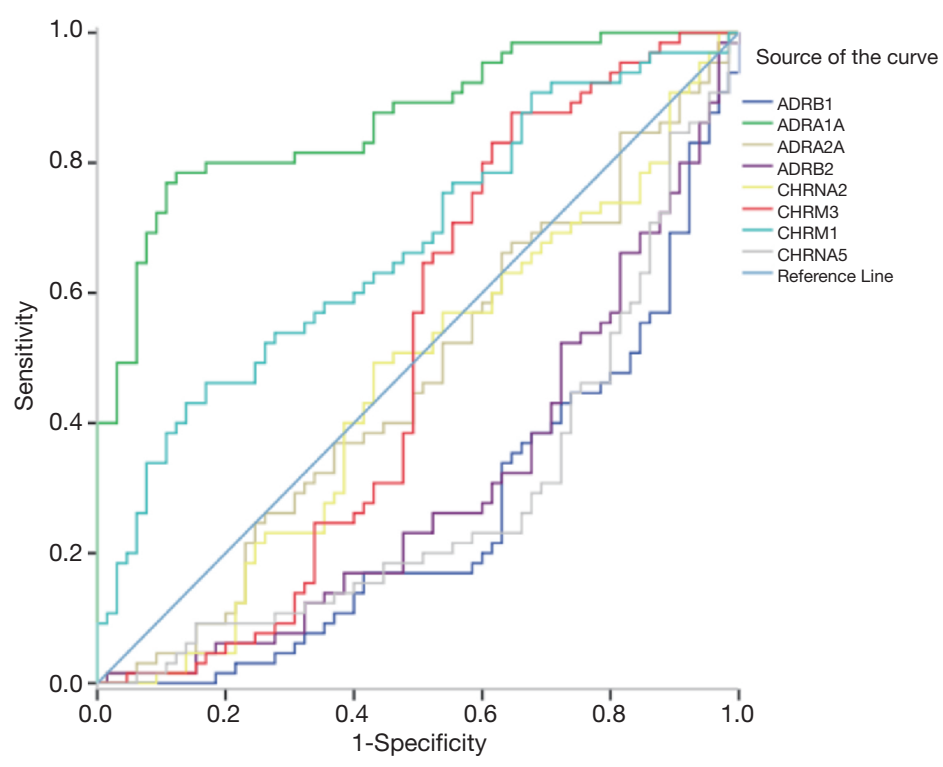

Area Under the Curve

\begin{tabular}{cccccc}
\hline \multirow{2}{*}{$\begin{array}{c}\text { Test Result } \\
\text { Variable(s) }\end{array}$} & Area & Std. Error & Asymptotic Sig. & Asymptotic 95\% Confidence Interval \\
\cline { 6 - 7 } & & & & Lower Bound & Upper Bound \\
\hline ADRB1 & 0.258 & 0.043 & 0.000 & 0.173 & 0.342 \\
ADRA1A & 0.866 & 0.031 & 0.000 & 0.805 & 0.928 \\
ADRA2A & 0.464 & 0.051 & 0.483 & 0.365 & 0.564 \\
ADRB2 & 0.306 & 0.046 & 0.000 & 0.215 & 0.396 \\
CHRNA2 & 0.458 & 0.051 & 0.409 & 0.358 & 0.558 \\
CHRM3 & 0.503 & 0.054 & 0.954 & 0.398 & 0.608 \\
CHRM1 & 0.674 & 0.047 & 0.001 & 0.582 & 0.766 \\
CHRNA5 & 0.287 & 0.046 & 0.000 & 0.197 & 0.377 \\
\hline
\end{tabular}

Figure 2 ROC curve for the diagnosis of $\mathrm{PCa}$ and relative AUC. ROC, receiver operating characteristic curve; PCa, prostate cancer; AUC, area under curve; ADRA, adrenoceptor alpha; ADRB, adrenoceptor beta; CHRM, cholinergic receptor, muscarinic; CHRNA, cholinergic receptor nicotinic alpha.

to-periphery network. The articles are from 1998 to 2007, and the prostate was among the labeled organs in all articles $(2,10,11,15,16)$. In the study of spinal interneurons, dorsal gray commissure (DGC) was detected in almost all cases. In the brain, raphe pallidus, the A5 noradrenergic cell region, locus coeruleus (LC) and hypothalamus are most widely detected using PRV.

\section{Effect of autonomic nerve receptors on the PCa diagnosis}

After univariate logistic regression analysis, ADRA1A was most positively correlated with the area under the curve (AUC), and the area was $0.866(\mathrm{P}<0.001)$. Furthermore, ADRB1 and CHRNA5 can also be detectors to help with PCa diagnosis, with AUC values of 0.258 and 0.287 , respectively $(\mathrm{P}<0.001)$. With multiple logistic analysis,
$\operatorname{Logit}(\mathrm{P})=-0.281 \times \mathrm{ADRB} 1+0.447 \times \mathrm{ADRA} 1 \mathrm{~A}+0.141$ $\times$ CHRM1 -1.383 is formulated as a predictor for $\mathrm{PCa}$ diagnosis. The data are shown in Figure 2. Moreover, for the most significantly changed gene, ADRA1A shows correlation with Gleason's score (GS) (Pearson's correlation $=-0.242, \mathrm{P}=0.05)$. In different GS groups, as is shown in Figure 3, there is significantly decreased in ADRA1A expression in higher GS group compared with the individuals with GS $=7$.

\section{Correlation between oncogenes and ADRA1A as well as ADRB1}

With the Pearson's correlation analysis, ADRA1A as well as ADRB1 were for the relationship with the expression of ERG, AKT1 and PTEN. The results are shown in 
Figure 4, which presents that ADRA1A is significantly positively correlated with ERG and PTEN, while ADRB1 is negatively related with the two oncogenes.

\section{Discussion}

This study confirms the close relationship between

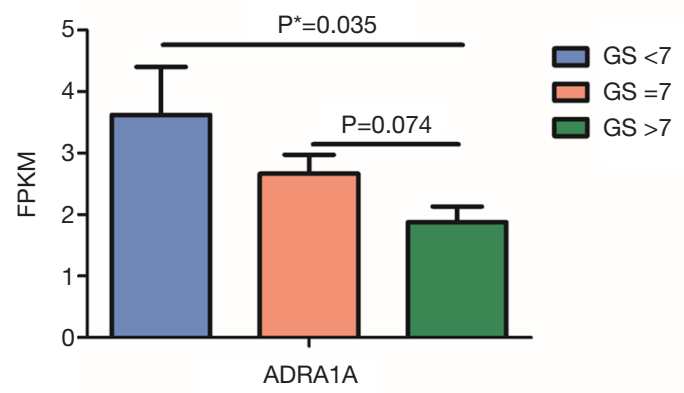

Figure 3 ADRA1A expression according to different GS groups. *, $\mathrm{P}<0.05$. Error bars indicate SEM. ADRA1A, adrenoceptor alpha 1A; GS, Gleason's score; FPKM, fragments per kilobase of exon model per million reads mapped; SEM, standard error of the mean. autonomic nerves and the generation and development of PCa. Moreover, it analyzed the expression of various receptors and the development of $\mathrm{PCa}$, clarifying the heterology of autonomic nerve control for the prostate. In this way, it is known that sympathetic and parasympathetic receptors are expressed differently in benign prostate diseases and malignant diseases, contributing to the microenvironment needed by the tumor $(8,9)$. In this regulation, the central circuit also tends to play an important role because the zones in the central nervous system controlling autonomic nerves are also significantly labeled when retrograde tracing is performed on the prostate. Thus, central-peripheral regulation is an important mediator of PCa development.

The autonomic nervous system contains two main divisions-the sympathetic nervous system (SNS) and PSNS. Different from the sensory nervous system, the autonomic nervous system regulates the body's unconscious actions and homeostasis. There are short preganglionic neurons (which release Ach, a neurotransmitter that can activate nicotinic Ach receptors on postganglionic neurons) and long postganglionic neurons (which release norepinephrine to activate adrenergic receptors peripherally) (17). Mostly, they originate from the brain
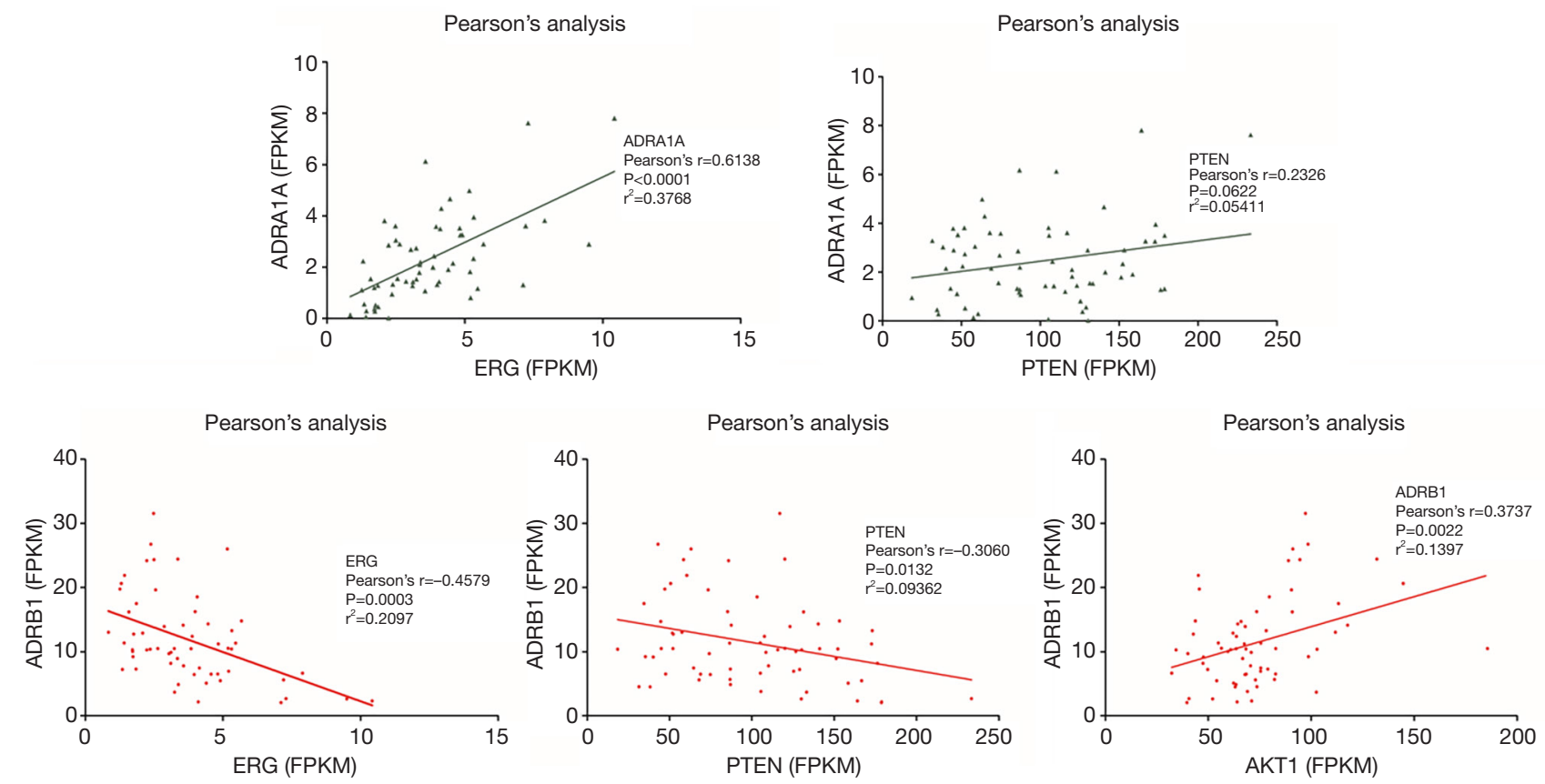

Figure 4 The Pearson's correlation between oncogenes and autonomic nerve receptors which are most significantly changed. ADRA, adrenoceptor alpha; ADRB, adrenoceptor beta; FPKM, fragments per kilobase of exon model per million reads mapped. 
stem and thoracolumbar region of the spinal cord. PSNS nerve fibers arise from the central nervous system, including the vagal nerve. Specifically, the pelvic splanchnic nerves also act as parasympathetic nerves, which control the hemostasis of the bladder, prostate and corpus cavernosum (18). However, because there are plexuses before dispersal to the target organ, the nerves are always mixed autonomic fibers containing parasympathetic and sympathetic ones. Efferent parasympathetic nerve signals are carried from the central nervous system to their targets by a system of two neuronal types, including presynaptic neurons, whose cell bodies are in the central nervous system and extend to postganglionic neurons peripherally embedded in their target organ (19). In this way, the signals are delivered from the central nervous system to the peripheral organs to regulate the whole-body and tumor development. However, no exact correlation was observed between the expression of the studied receptors and PCa clinical progression. Only the correlation between the PSA levels and ADRB1, ADRA1A, ADRA2A and CHRNA2 was observed, as shown Tables S1,S2. The parasympathetic nerve fibers deliver chiefly Ach as the neurotransmitter, especially to the muscarinic Ach receptor ( $M$ receptor) (5). Thus, the aging of the brain may regulate or stimulate the process of the peripheral organs through the parasympathetic nerve fibers. In the center, the raphe pallidus, A5 noradrenergic cell region, LC and hypothalamus are most widely detected using the PRV, as was reviewed previously $(2,10,11,15,16)$. These areas are closely related to the activity of autonomic nerves. LC mediates many of the sympathetic effects, and Barrington's nucleus lies in the LC projecting to the sacral parasympathetic nucleus (20). The nucleus raphe pallidus (whose main response is for tachycardia and fever) receives afferent connections from the paraventricular nucleus $(\mathrm{PVN})$ of the hypothalamus, in which GABA is a mediator of the sympathetic system. The autonomic zone of the gray matter in the hypothalamus is also a center for the sympathetic (anterior hypothalamus) and parasympathetic (posterior hypothalamus) nervous system (21). We summarized the above in Figure 4, suggesting the hypothesis of the central regulation for the $\mathrm{PCa}$.

Several studies have previously described a phenomenon called perineural invasion in $\mathrm{PCa}$, indicating that tumor cells grow and migrate along native nerve fibers because of the surrounding microenvironment $(3,4)$. Sensory nerves can always be related to tumor-associated pain, but only the autonomic nerves have been implicated in tumor progression by the delivery of hormones or signals from their termini. This process also indicates a poor prognosis and quick development. It may be that the hormones or signals delivered by the nerves promote PCa growth in each stage of development $(8,9,22)$. It was also suggested by Magnon et al. that the tumor itself is infiltrated by the newly developed autonomic nerve regulating cancer initiation and progression through in vivo study in mice (9). Later, in 2017, they demonstrated that adrenergic nerves activate an angiometabolic switch in PCa based on their previous study. They reported that the loss of endothelial ADRB2 leads to the inhibition of angiogenesis through strengthening of endothelial oxidative phosphorylation with the help of Cox10, indicating this cross-talk between nerves and endothelial metabolism could be targeted as an anticancer therapy (8). Although some reports have confirmed the effect of autonomic nerves on tumors, the role of nerves in cancer initiation and progression has remained unclear. Additionally, many different autonomic nerve receptors exist in the target tissue, and their correlation and function remain unclear. In prostate tissue, as this report has suggested, the levels of ADRA1A, ADRA2A, ADRB1, ADRB2, CHRM1, CHRM3, CHRNA2 and CHRNA5 in PCa tissues were significantly different from those of benign prostate diseases. We also confirmed these results in the TCGA database, and the significance of CHRM1 was opposite, likely caused by racial differences and the fact that the prostate tissue is adjacent to the cancer. These variations between cancer and benign tissue may also contribute to the difference in the muscle activation caused by autonomic nerves. More concise medicines could be treated for the urine and urination symptoms caused by PCa.

The center-periphery circuits play important roles in various diseases, including the connection between central neurons and organs such as the stomach, pancreas, and liver. The connection mainly includes nerve-nerve and nerve-hormone target pathways, as previously reported (23). In the prostate, as is shown in Figure 5, these relationships also exist in hypothalamus-prostate regulation (24). As suggested, some peptides, oxytocin, adiponectin, ghrelin, and leptin are secreted by central neurons released to the peripheral circulation for regulation. Moreover, the autonomic nerves tend to stimulate smooth muscle in the prostate through the function of receptors. Deferent prostatic zones contain cholinergic fibers that may exceed that of adrenergic fibers in the overall prostate gland. In several studies, AChE-positive fibers were found to contain transmitters such as vasoactive intestinal peptide, neuropeptide Y (NPY), or NO. These transmitters are 


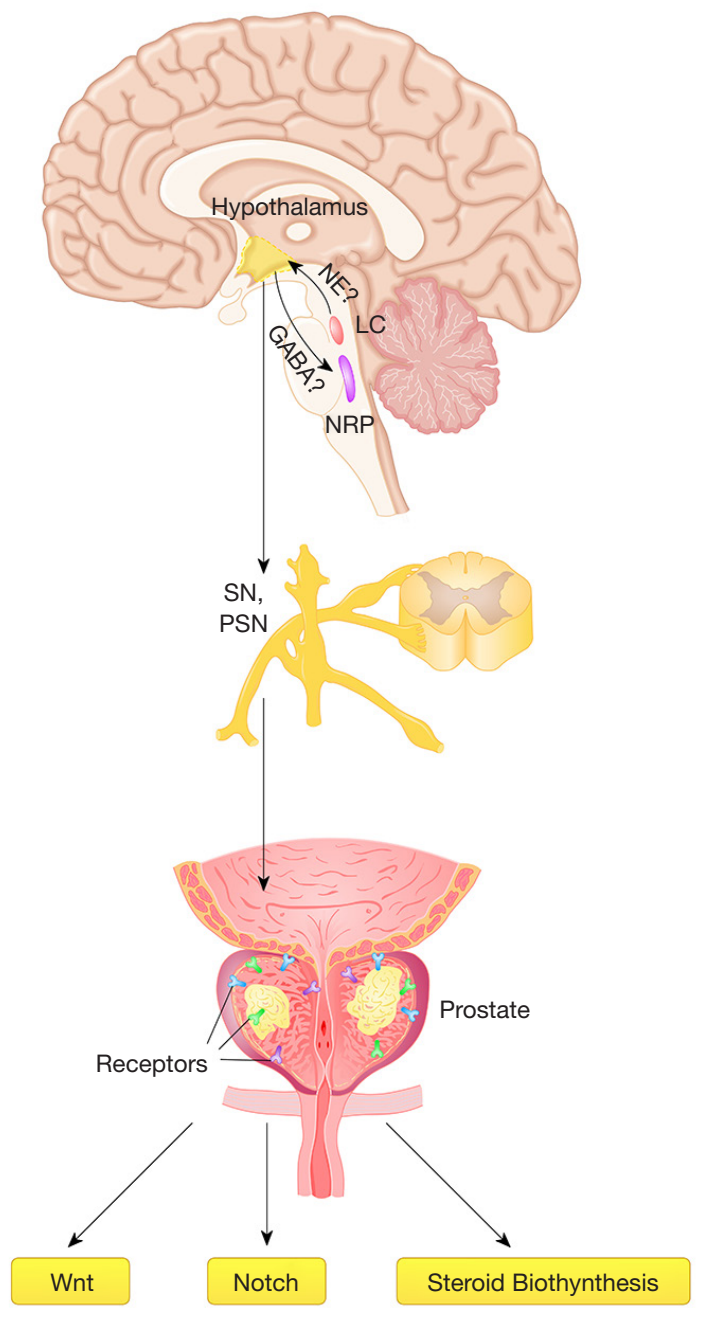

Figure 5 Schematic for the hypothesis of the central regulation for prostate. The autonomic nerves from the center, especially from the hypothalamus, regulate the microenvironment and the cell signals of the prostate. SN, sympathetic nervous; PSN, parasympathetic nervous.

also contained in other tissues. Thus, the nerve fibers transfer the signals from the central to the peripheral prostate. However, the function of the normal prostatic epithelium and how muscarinic receptor agonists stimulate proliferation in PCa cell lines, specifically in PC3, DU145, and LNCaP cells, remain unclear. Thus, the receptor agonist functions in transmitter release, contraction, prostatic secretion, and prostatic growth, as summarized by Witte et al. (5). They also suggested that most muscarinic receptors are found in the prostatic epithelium. M2 receptors on stromal smooth muscle cells quantitatively play a smaller role than M1 receptors on epithelial cells or a1A-adrenoceptors on smooth muscle cells, affecting signal transduction and smooth muscle and epithelial cell function. Additionally, the autonomic nerve receptor tends to contribute to the cancer microenvironment by changing the signaling pathways, as observed in our GSEA results. Moreover, steroid biogenesis, as suggested, is related to the expression of androgen and estrogen, which are quite important for PCa and breast cancer development (25). To analyze the diagnosis, ADRA1A was most positively correlated, with an AUC of $0.866(\mathrm{P}<0.001)$, indicating that ADRA1A is a potential candidate for PCa diagnosis.

In this study, we detected different autonomic nerve receptors and reviewed the central control of the peripheral organs, including the prostate. In this way, it is easier to understand that central prostate regulation may play a significant role in PCa generation and development. This report has several limitations. First, only prostate tissues from the Chinese population were analyzed, although confirmation was conducted using the TCGA database. Second, more mechanisms should be investigated according to the above results. Third, medicine-based treatment might be used according to the receptor variations in the clinical study in the future to determine the changes and effects.

In conclusion, central-peripheral regulation plays an important role in the generation and development of PCa. This regulation may alter the micro-environment, delivering proliferative and nutritional factors to the tumor. Thus, it might be possible to modulate the pathological process of $\mathrm{PCa}$ to treat the disease.

\section{Acknowledgments}

Funding: This work was supported by the Precision Medicine Program of Second Military Medical University (2017JZ35, Fubo Wang).

\section{Footnote}

Reporting Checklist: The authors have completed the MDAR reporting checklist. Available at http://dx.doi.org/10.21037/ tcr-20-2053

Data Sharing Statement: Available at http://dx.doi. org/10.21037/tcr-20-2053

Conflicts of Interest: All authors have completed the ICMJE 
uniform disclosure form (available at http://dx.doi. org/10.21037/tcr-20-2053). The authors have no conflicts of interest to declare.

Ethical Statement: The authors are accountable for all aspects of the work in ensuring that questions related to the accuracy or integrity of any part of the work are appropriately investigated and resolved. The study conformed to the provisions of the Declaration of Helsinki (as revised in 2013). Written informed consents were obtained from the participants before sampling. The study was approved by the Clinical Research Ethics Committee of Shanghai Changhai Hospital of Second Military Medical University (No. 2017JZ35). All of the data are from public database or papers have already published.

Open Access Statement: This is an Open Access article distributed in accordance with the Creative Commons Attribution-NonCommercial-NoDerivs 4.0 International License (CC BY-NC-ND 4.0), which permits the noncommercial replication and distribution of the article with the strict proviso that no changes or edits are made and the original work is properly cited (including links to both the formal publication through the relevant DOI and the license). See: https://creativecommons.org/licenses/by-nc-nd/4.0/.

\section{References}

1. Torre LA, Bray F, Siegel RL, et al. Global cancer statistics, 2012. CA Cancer J Clin 2015;65:87-108.

2. Zermann DH, Ishigooka M, Doggweiler R, et al. Central nervous system neurons labeled following the injection of pseudorabies virus into the rat prostate gland. Prostate 2000;44:240-7.

3. Villers A, McNeal JE, Redwine EA, et al. The role of perineural space invasion in the local spread of prostatic adenocarcinoma. J Urol 1989;142:763-8.

4. Maru N, Ohori M, Kattan MW, et al. Prognostic significance of the diameter of perineural invasion in radical prostatectomy specimens. Hum Pathol 2001;32:828-33.

5. Witte LP, Chapple CR, de la Rosette JJ, et al. Cholinergic innervation and muscarinic receptors in the human prostate. Eur Urol 2008;54:326-34.

6. Ruggieri MR, Colton MD, Wang P, et al. Human prostate muscarinic receptor subtypes. J Pharmacol Exp Ther 1995;274:976-82.

7. Ventura S, Pennefather J, Mitchelson F. Cholinergic innervation and function in the prostate gland. Pharmacol Ther 2002;94:93-112.

8. Zahalka AH, Arnal-Estape A, Maryanovich M, et al. Adrenergic nerves activate an angio-metabolic switch in prostate cancer. Science 2017;358:321-6.

9. Magnon C, Hall SJ, Lin J, et al. Autonomic nerve development contributes to prostate cancer progression. Science 2013;341:1236361.

10. Nadelhaft I, Miranda-Sousa AJ, Vera PL. Separate urinary bladder and prostate neurons in the central nervous system of the rat: simultaneous labeling with two immunohistochemically distinguishable pseudorabies viruses. BMC Neurosci 2002;3:8.

11. Huddleston GG, Song CK, Paisley JC, et al. Gonadal steroid receptors colocalize with central nervous system neurons projecting to the rat prostate gland. Am J Physiol Regul Integr Comp Physiol 2007;292:R2196-205.

12. Trapnell C, Williams BA, Pertea G, et al. Transcript assembly and quantification by RNA-Seq reveals unannotated transcripts and isoform switching during cell differentiation. Nat Biotechnol 2010;28:511-5.

13. Myers MG Jr, Olson DP. Central nervous system control of metabolism. Nature 2012;491:357-63.

14. Jobling P, Pundavela J, Oliveira SM, et al. Nerve-cancer cell cross-talk: a novel promoter of tumor progression. Cancer Res 2015;75:1777-81.

15. Orr R, Marson L. Identification of CNS neurons innervating the rat prostate: a transneuronal tracing study using pseudorabies virus. J Auton Nerv Syst 1998;72:4-15.

16. Xu C, Yaici ED, Conrath M, et al. Galanin and neurokinin-1 receptor immunoreactive [corrected] spinal neurons controlling the prostate and the bulbospongiosus muscle identified by transsynaptic labeling in the rat. Neuroscience 2005;134:1325-41.

17. McCorry LK. Physiology of the autonomic nervous system. Am J Pharm Educ 2007;71:78.

18. Espinosa-Medina I, Saha O, Boismoreau F, et al. The sacral autonomic outflow is sympathetic. Science 2016;354:893-7.

19. Moro C, Uchiyama J, Chess-Williams R. Urothelial/ lamina propria spontaneous activity and the role of $\mathrm{M} 3$ muscarinic receptors in mediating rate responses to stretch and carbachol. Urology 2011;78:1442.e9-15.

20. Valentino RJ, Chen S, Zhu Y, et al. Evidence for divergent projections to the brain noradrenergic system and the spinal parasympathetic system from Barrington's nucleus. Brain Res 1996;732:1-15.

21. Nakamura K, Matsumura K, Kaneko T, et al. The rostral 
raphe pallidus nucleus mediates pyrogenic transmission from the preoptic area. J Neurosci 2002;22:4600-10.

22. Ayala GE, Dai H, Tahir SA, et al. Stromal antiapoptotic paracrine loop in perineural invasion of prostatic carcinoma. Cancer Res 2006;66:5159-64.

23. Xu H, Fu S, Chen Y, et al. Oxytocin: its role in the benign prostatic hyperplasia $(\mathrm{BPH})$ via the ERK pathway. Clin Sci
(Lond) 2017;131:595-607.

24. Xu H, Fu S, Chen Q, et al. The function of oxytocin: a potential biomarker for prostate cancer diagnosis and promoter of prostate cancer. Oncotarget 2017;8:31215-26.

25. Auchus ML, Auchus RJ. Human steroid biosynthesis for the oncologist. J Investig Med 2012;60:495-503.

Cite this article as: Liu F, Xu H, Chen J, Yang B, Zhao L, Ji J, Cao Z, Lyu J, Wang F. Autonomic nerve regulation for prostate cancer: study based on the tissue transcriptional analysis. Transl Cancer Res 2020;9(11):6755-6767. doi: 10.21037/tcr-20-2053 